\title{
ENSAIOS
}

\section{A AUTOCRÍTICA COMO DESAFIO ÉTICO-POLÍTICO DE RESISTÊNCIA NO CONTEMPORÂNEO}

Self-Criticism As an Ethical-Political Challenge of Resistance in Contemporaneity

DOI: 10.14393/LL63-v36n1-2020-13

Décio Rocha*

RESUMO: Centrando-se particularmente no território da Educação, o artigo tematiza os ataques que vêm sendo desferidos na atualidade contra as humanidades e aponta a necessidade de uma autocrítica como exercício ético de corresponsabilização face ao desgaste das esquerdas. Denominando como ficções do contemporâneo as ações baseadas em uma perspectiva neoconservadora em afinidade com uma ótica neoliberal que muitas vezes se atualizam sob a forma de leis, o artigo explicita iniciativas que poderiam se contrapor às referidas formulações não democráticas. O conceito de humanidades é então revisitado em suas alterações ao longo do tempo, buscando-se explicitar a ameaça que ele representa para o funcionamento do capitalismo financeiro. Finalmente, ao lado das ações que têm lugar numa dimensão macro, necessárias, mas insuficientes para a afirmação de uma perspectiva democrática, propõe-se uma reflexão sobre o plano micropolítico, com ênfase em práticas escolares de resistência que não sejam meramente reativas.

PALAVRAS-CHAVE: Humanidades. Docência. Neoconservadorismo. Resistência. Micropolítica.

ABSTRACT: Focusing particularly on the territory of education, this article addresses the attacks that have been made against humanities and the need for self-criticism as an ethical exercise of coresponsibility against the wear and tear of the Left. Considering as fictions of contemporaneity the actions based on a neoconservative perspective in tune with a neoliberal viewpoint that oftentimes is updated in the form of laws, it points to initiatives that could oppose such non-democratic formulations. The concept of humanities is revisited considering its changes over time, in an attempt to explain how it poses a threat to the functioning of financial capitalism. Finally, alongside actions that take place in a macro dimension, which are necessary, but insufficient to ensure a democratic perspective, it proposes a reflection upon the micropolitical plan, with emphasis on school practices of resistance that are not merely reactive.

KEYWORDS: Humanities. Teaching. Neoconservatism. Resistance. Micropolitics.

\footnotetext{
* Professor Titular do Departamento de Estudos da Linguagem do Instituto de Letras, Universidade do Estado do Rio de janeiro. ORCID: 0000-0003-2342-4976. E-mail: rochadm(AT)uol.com.br.
} 


\section{Introdução}

Uma iniciativa potencializadora para o corpo das práticas escolares foi o convite do Núcleo de Estudos Franco-Brasileiros (NEFB) do Colégio Pedro II para uma reflexão coletiva sobre a importância das humanidades e das linguagens no currículo escolar ${ }^{1}$. Trata-se, com efeito, de tema que exige toda a atenção, tendo em vista os reiterados ataques que a formação humanística vem sofrendo na contemporaneidade, além, é claro, do difícil debate acerca do modo como vem se produzindo na atualidade aquilo que tem sido chamado de "onda neoconservadora, alt-right, 'nova direita', crescimento da extrema direita, trumpização da política, populismos de direita, crise das esquerdas" (SOLANO, 2018, p. 3).

Para iniciar, retomo um trecho do epílogo de A difícil democracia. Reinventar as esquerdas, obra publicada em 2016 por Boaventura de Sousa Santos. Se começo pelo epílogo, começo, portanto, já pelo final. E em se tratando de um epílogo que o autor intitulou "Para ler em 2050: uma reflexão sobre a utopia ou sobre a sociologia das ausências das esquerdas", devo admitir o ato de desobediência que cometi, uma desobediência que se explica não apenas por não pretender estar por aqui em 2050, mas por um sentimento de profunda inquietação frente à iminência de um futuro cada vez mais desconcertante. Ao antecipar a voz do autor, passo a incluir o leitor no mesmo ato de desobediência:

Quando um dia se puder caracterizar a época em que vivemos, o espanto maior será que se viveu tudo sem antes nem depois, substituindo a causalidade pela simultaneidade, a história pela notícia, a memória pelo silêncio, o futuro pelo passado, o problema pela solução. Assim, as atrocidades puderam ser atribuídas às vítimas, os agressores foram condecorados por sua coragem na luta contra as agressões, os ladrões foram juízes, os grandes decisores políticos puderam ter uma qualidade moral minúscula quando comparada com a enormidade das consequências de suas decisões. (...) O insulto tornou-se o meio mais eficaz de um ignorante ser intelectualmente igual a um sábio. (SANTOS, 2016, p. 209)

\footnotetext{
${ }^{1}$ Uma primeira versão deste texto foi apresentada na jornada "Francês e interdisciplinaridade na formação humanística do CPII", organizada pelo Núcleo de Estudos Franco-Brasileiros (NEFB) do Colégio Pedro II, campus Centro, Rio de Janeiro, em 22 de agosto de 2019.
} 
Por que fazer a autocrítica, conforme o anuncia o próprio título deste texto? Porque quero ter uma parte minha no que está acontecendo. E quando falo de "minha parte", colocome como integrante de um coletivo que costumamos chamar de academia, profissionais da educação ou coisa que o valha. Por difícil que seja imaginar que nosso lugar de fala possa estar contribuindo para a produção de um cenário como o atual, nada encorajador sob muitos aspectos, não ter parte alguma no que acontece é pior, pois se supõe então que alguém de fora manipula os cordões das marionetes e nós, impotentes, nada fazemos senão responder aos comandos dados; ou então que os tempos que hoje vivemos são um destino, uma natureza sobre a qual nada podemos. Isso é algo que tampouco desejo admitir. Quero pensar que ainda podemos fazer algo, e ainda que se mostre inóspito o território que hoje habitamos, reivindico minha parte nesse latifúndio para proceder a uma autocrítica livre de culpa e de medo. Tão livre quanto possível.

Foi com esse objetivo que organizei este texto em cinco grandes tópicos: (1) Plano ficcional do contemporâneo nos trópicos; (2) Mas nem tudo é fiç̧ão; (3) O que (não) temos feito para impedir tudo o que vai mal?; (4) Por que as humanidades incomodam? Finalmente, (5) Macropolítica e micropolítica. Passemos ao primeiro desses tópicos.

\section{Plano ficcional do contemporâneo nos trópicos}

Vivemos tempos pré-pitagóricos de terraplanistas, de nazismos ditos de esquerda, de desautorização dos avanços da teoria darwiniana da evolução. Tempos em que as pessoas querem se convencer de que nunca houve massacre de indígenas, nem escravidão no Brasil. Uma verdadeira "desleitura" do mundo, ou uma leitura feita não se sabe com que qualidade de lentes que inviabilizam uma problematização do cotidiano; práticas que, por naturalizarem esse cotidiano, precisam demonizar propostas que sinalizam a possível construção de uma vida desejada, como nos indica Paulo Freire. Atravessamos tempos em que se constroem fantasmas que se deseja caçar - como é o caso das "ideologias de gênero", talvez uma das mais bem lapidadas peças de ficção dentre todas, já que produzida e nomeada exatamente pelos mesmos atores, isto é, por seus detratores, que inventam sua existência, nomeiam-na, atemorizam-se diante do que produziram e se põem a combatê-la o mais obsessivamente possível. Tempos de fake news, e de outras news que de fake só têm a aparência, como é o caso do Programa Escola 
Mais Segura², anunciado em 05 de julho de 82019 por João Dória e pelo secretário de Educação de São Paulo, Rossieli Soares, que, para combater a violência manifestada em eventos como os de Suzano (13 de março de 2019) e Carapicuíba (30 de maio de 2019)³, recorrem à militarização das escolas como "procedimentos de segurança": (i) policiamento nas unidades escolares; (ii) criação de um regimento escolar comum para todas as escolas da rede; (iii) alocação de psicólogos e assistentes sociais nas diretorias regionais de ensino para monitoramento do comportamento de alunos e consequente "melhoria" do clima escolar; (iv) responsabilização dos atores da escola, exigindo-se atitudes mais enérgicas em casos de depredação e violência contra professores. Não é difícil prever a ineficácia de todos os dispositivos aqui elencados para resolver o problema. Como também não é difícil prever o estrondoso fracasso que aguarda o dispositivo pensado pela Secretaria Estadual de Educação do Estado do Rio de Janeiro também destinado a evitar episódios de violência nas escolas - o chamado "botão do pânico", tecnologia utilizada por militares egressos das Forças Armadas contratados como porteiros e inspetores ${ }^{4}$.

Esses mesmos ares de ficção também se estendem ao tratamento conferido pelo atual ministro da Educação brasileiro, Abraham Weintraub, aos cursos superiores de sociologia e filosofia, quando Ihes promete corte de investimentos. Segundo anunciado em 26 de abril de 2019, a notícia gerou comentários indignados na imprensa internacional, com manifestação do repúdio de diversos cientistas sociais e associações de estudos em sociologia. Uma manchete do jornal Le Monde, de 6 de maio, dizia que "no Brasil, as ciências sociais e as humanidades não são um luxo". De forma mais geral, a equivocada iniciativa do governo se insere em um quadro de luta contra "projetos com viés ideológico", sempre promovidos pelos saberes ditos "inúteis", que é como se referem à literatura, à filosofia, às artes e outros mais.

Não faltam argumentos no sentido de mostrar que esse plano ficcional desempenha papel estratégico importante em duas frentes. Um psicanalista de São Paulo, Marcos Donizetti,

\footnotetext{
2 Consulta realizada no sítio 1.folha.uol.com.br/cotidiano/2019/07/governo-de-sp-fara-projeto-piloto-compolicial-da-reserva-dentro-de-escola.shtml.

3 Consultar os sítios g1.globo.com/sp/mogi-das-cruzes-suzano/noticia/2019/03/13/cronologia-massacre-emsuzano.ghtml; g1.globo.com/sp/sao-paulo/noticia/2019/06/03/alunos-sao-suspensos-por-arremessar-livros-ecarteiras-em-professora-em-carapicuiba.ghtml.

${ }^{4}$ Divulgado em 28 de julho de 2019, no sítio odia.ig.com.br/rio-de-janeiro/2019/07/5667248-pedro-fernandes--nao-estamos-militarizando-a-rede-estadual-de-educacao.html\#foto=1.
} 
assim resume tal estratégia: primeiro, uma declaração absurda toma de assalto as redes sociais e acaba controlando as pautas dos noticiários e das conversas em geral entre as pessoas; a indignação produzida gera um efeito catártico que mobiliza a todos; enquanto isso, uma emenda constitucional contrária aos interesses da população é votada, e acaba faltando energia dessa mesma população para afrontá-la e barrá-la, o que gera nas pessoas paralisação e medo. Por isso, a lição deixada pelo psicanalista: "é necessário ser 'seletivo' com sua indignação" (DONIZETTI, 2018).

\section{Mas nem tudo é ficção}

Eis, portanto, o problema. Diante de tantos episódios que teriam tudo para figurar numa cena ficcional (de muito mau gosto, claro), materializando aquilo que Eliane Brum (2019) denominou "autoverdade" ${ }^{5}$, o fato é que não é ficção, por exemplo, a onda de preconceitos que se espalha insidiosamente por todos os lados, já por muitos qualificada de anti-intelectualista (LADEIRA, 2019).

Preconceitos funcionam regularmente a partir de uma lógica binária, bem simples, numa espécie de perspectiva identitária mais ou menos petrificada: existe o bandido e o cidadão de bem, o superior e o inferior, numa polarização que se ajusta perfeitamente a um certo consumismo acrítico contemporâneo, que não é apenas um consumismo de mercadorias, mas também de ideias. O ódio parece ser o afeto básico que move o preconceito, um ódio que se volta contra a ameaça libertária do saber. Na realidade, o preconceito implica que a lógica do pensamento passe a trabalhar com categorias pré-modernas como o "messianismo" e a "peste" 6 , pois desaparecem o saber e a educação. Valores pré-modernos que se afinam muito bem com ideias como as de Terra plana, que já mencionamos.

A aliança entre a racionalidade neoliberal e o neoconservadorismo exige, para legitimar suas ideologias, a desqualificação de seus alvos: fica mais fácil o ataque à coisa pública, aos pobres, às mulheres, aos negros, aos indígenas, ao meio ambiente, enfim, a tudo aquilo que no planeta pode se interpor aos interesses do capital, se esses alvos são apresentados como

\footnotetext{
5 "Valorização de uma verdade pessoal e autoproclamada", onde "o valor está no ato de dizer e não no conteúdo do que é dito" (BRUM, 2018). A verdade estaria situada naquilo que alguém deseja / designa como verdadeiro.

${ }^{6}$ Debate promovido por Marcia Tiburi e Rubens Casara, revista CULT, 12 de outubro de 2016.
} 
inferiores ou não merecedores de uma existência digna. Naturaliza-se um pretenso deficit encontrado precisamente naquilo que incomoda e que se deseja aniquilar.

Temos visto diversos ataques estratégicos como a PEC 241, de junho de 2016, transformada em Emenda Constitucional 95, de dezembro de 2016, a qual institui novo regime fiscal para um período de 20 anos, gerando efeitos preocupantes por congelar as verbas públicas destinadas a serviços essenciais; o mesmo em relação à reforma trabalhista, Lei 13.467, de 13 de julho de 2017, que, dentre outras alterações, modifica a CLT em matéria de terceirização de serviços, jornada de trabalho, vínculo empregatício, férias, rescisão contratual, dentre outras alterações. Uma reforma que legaliza o trabalho em condições degradantes.

A chamada Reforma do Ensino Médio (Lei 13.415, de 16 de fevereiro de 2017) é outra amostra de não ficção que veio atingir bem diretamente um campo que é aquele no qual nos movemos enquanto professores. A partir da Medida Provisória 746, de 22 de setembro 2016, cujos proponentes foram Michel Temer e Mendonça Bezerra Filho, então ministro da Educação, a referida lei veio instituir, sem qualquer debate mais ampliado com a sociedade, a língua inglesa como única obrigatória, sendo facultada a oferta, em caráter optativo, de outras línguas, preferencialmente o espanhol. E em seu inciso $V$ do caput do artigo 36, desferiu um novo golpe contra o ensino ao abrir a possibilidade de profissionais com notório saber, não detentores da formação de professor, poderem ministrar conteúdos nas escolas. Além da limitada perspectiva em matéria de educação, a iniciativa dá provas de uma inoportuna versão do trabalho empreendido pelo professor, que se reduz, então, a mero "difusor de conteúdos".

Um mesmo modo de procedimento centralizador caracterizou a instituição da Base Nacional Comum Curricular (BNCC), quando, concluída a segunda fase de debates, se dispensou a participação do grupo de especialistas que vinha construindo a proposta, sendo então os trabalhos concluídos ao (dis)sabor dos consensos entre MEC e iniciativa privada: uma primeira versão que alterou a Base do Ensino Infantil e Fundamental foi assim homologada em 20 de dezembro de 2017, e a segunda, que altera a do Ensino Médio, em 14 de dezembro de 2018. Uma ficção como processo, mas realidade como efeito.

Desde 2004, uma outra iniciativa bastante nociva vem se interpondo ao trabalho que se realiza nas escolas, a pretexto de combater uma educação pretensamente dominada pelo comunismo, onde professores não ensinariam o que é devido, mas difundiriam ideologias que 
interfeririam na educação moral que as famílias gostariam de dispensar a seus filhos, uma escola que faria a apologia de um modo de ser destruidor da família porque baseado em comportamentos marcados por uma moral pervertida, animado por uma certa "teoria do gênero". Trata-se do movimento Escola sem Partido, criado no Brasil pelo advogado Miguel Nagib para representar pais e professores preocupados com a "contaminação político-ideológica" promovida nas escolas brasileiras por "militantes disfarçados de professores". A partir de 2014, o movimento ganhou espaço com a confecção de projetos de lei, popularmente chamados de "lei da mordaça", que pretendiam impor limites à participação dos professores em sala de aula.

Em entrevista ao jornal O Globo ${ }^{7}$, Miguel Nagib anunciou para o mês de agosto de 2019 a suspensão das atividades do movimento, alegando como motivo a falta de apoio político do presidente da república, atitude que contraria promessas e expectativas criadas durante o período de campanha. De qualquer modo, o prejuízo já se faz sentir: está cada vez mais difícil formar professores hoje, porque ninguém se sente atraído pela profissão. A lógica produtivista e o obscurantismo, ou, como diz Rolnik (2018) com muita propriedade, o neoliberalismo em sua versão financeira e o neoconservadorismo desempenharam bastante bem o seu papel.

Se os itens elencados neste tópico não forem ainda suficientes para se perceber o que há de concreto e de nocivo em toda essa ficção que pesa em nossos cotidianos, basta lembrar a reforma da previdência que, no momento de escritura deste texto, ainda se encontra em curso.

\section{0 que (não) temos feito para impedir tudo o que vai mal?}

De que modo estamos colaborando para oportunizar ou, pelo menos, para não frear todas essas atrocidades? Como disse no início, considero mais realista - e também mais otimista - pensar que temos algo a ver com o modo como as coisas acontecem. Dou um exemplo: por ocasião da elaboração dos PCN, a partir de 1998, pensou-se que uma saída possível para a difícil condição das salas de aula de língua estrangeira fosse o trabalho de leitura. Uma saída que, com certeza, era mais atraente do que a velha aula de gramática, na qual todos os anos se conjugava o mesmo verbo no quadro-negro e dali não se avançava. Pois bem, mais de 20 anos se passaram e apenas o quadro-negro se modificou - hoje temos quadros brancos sobre os quais escrevemos

\footnotetext{
${ }^{7}$ O Globo, 18 jul. 2019.
} 
com canetas especiais, não ainda exatamente em todas as escolas, é claro! As medidas tomadas em relação ao trabalho com língua estrangeira na escola só dificultaram o encontro de professores e alunos. As salas de aulas cada vez mais repletas e a ínfima carga horária de trabalho destinada às disciplinas de língua estrangeira, por exemplo, permanecem até hoje, apresentando-se como fenômeno natural algo que, na realidade não passa de decisão de burocratas que não sabem que nem mesmo leitura se pode efetivamente trabalhar com 40 alunos em sala! Penso ter sido um erro ter apostado em uma "solução temporária" sem qualquer garantia de que o governo se comprometeria com providências para um futuro mais promissor

para as escolas. É por isso que considero importante apostar em nossas implicações, porque, assim, podemos rever o sentido de nossas ações e buscar novos rumos para elas. Ou então continuaremos a carregar (sozinhos) a culpa de nada acontecer na aula de língua estrangeira. Passo, deste modo, ao primeiro subitem que considero fundamental em relação àquilo que nos falta fazer.

\subsection{Lutar pela (res)significação das palavras}

Se nos dispusermos a procurar nossa parte em tudo o que vem acontecendo, diremos, em primeiro lugar, que não temos resistido o suficiente a um certo modo de ver e de significar típico da contemporaneidade. Com efeito, fala-se hoje de formação continuada, de flexibilização, de excelência, como se tudo isso fosse uma invenção recente, como se não tivéssemos sempre desejado promover avanços gratificantes em nossas ações. Penso que não enfatizamos, como seria devido, que o que ocorre é o que chamamos, em uma perspectiva discursiva, de luta pela significação das palavras. Afinal, as palavras significam dentro de uma dada formação discursiva. Não é a excelência, a qualidade ou a formação continuada que se configuram como uma novidade, mas um certo modo de praticar tais conceitos; um modo que, inclusive, é aquilo que rejeitamos na atualidade. Com efeito, rejeitamos uma formação continuada que não dê conta da dimensão política da atuação do professor, ou que aponte para cursos online a fim de driblar uma falta de tempo do docente, "falta de tempo" que resulta dos magros salários que são pagos e que, por consequência, geram uma excessiva de carga de trabalho para o professor. O que rejeitamos é um certo sentido de formação continuada que acaba coincidindo com a mera aquisição de técnicas ou uma maior familiaridade com as novas tecnologias. Rejeitamos a 
culpabilização do professor que não estaria exercendo a contento a função de mediador ou facilitador do conhecimento, quando, na realidade, os resultados insuficientes dos alunos se devem no mínimo a um leque bem mais diversificado de razões.

Na atualidade, o discurso da competência e o léxico da excelência sustentam uma forma ideológica que já foi denominada por Tatián (2017) "progressismo reacionário". Como arremedo de progresso, uma certa retórica meritocrática impede o exercício da imaginação crítica e só reconhece como novidade possível a indefinida reprodução do capital. Na verdade, qualidade sempre foi um objetivo a ser alcançado, mas nem sempre se entendeu por qualidade aquilo que hoje se expressa em conformidade com a lógica do mercado. Também sempre se assistiu à mesclagem de saberes que se acumulam e se alteram, mas apenas recentemente se tem buscado contabilizar essas modificações em nome de uma formação permanente.

A possibilidade de um mesmo vocábulo percorrer diferentes formações discursivas, produzindo, portanto, efeitos de sentido variados pode ser constatada, por exemplo, nos diferentes usos do termo révolution por ocasião da eleição presidencial de 2017 na França: a révolution preconizada pelo partido comunista Lutte Ouvrière, representado por Nathalie Arthaud, e a Révolution, título da obra lançada ao final de 2016 pelo candidato de centro-direita Emmanuel Macron. O mesmo poderia ser dito acerca do combate entre "discurso de ódio" e "liberdade de expressão", ou da polissemia criada para socialismo, ou ainda democracia ${ }^{8}$. Na passagem de um posicionamento (MAINGUENEAU, 2004, p. 392) para outro, muitas vezes não é suficiente a mera ressignificação do vocábulo, e se recorre à produção de reformulantes que muitas vezes ganham ares de eufemismos: "ditadura militar" é, desse modo, substituída por "regime militar", "golpe de estado" por "revolução" e "tortura" por "práticas de extração de informação"9. A esse respeito, é oportuno retomarmos a lição deixada por Hardt e Negri (2018, p. 16) que, ao reivindicarem uma nova acepção para o conceito de empreendedorismo, fora dos parâmetros neoliberais, reconhecem com muita propriedade que "uma das tarefas cruciais do pensamento político é combater no campo dos conceitos, esclarecendo-lhes ou transformando-

\footnotetext{
${ }^{8}$ Uma definição de democracia baseada na ótica das novas direitas é "sistema caótico no qual os corruptos governam, aberto para qualquer excesso (...)" (SOLANO, 2018, p. 24)

${ }^{9}$ Disponível em: https://www1.folha.uol.com.br/opiniao/2018/10/o-nome-das-coisas-e-o-reizinhomandao.shtml?loggedpaywall.
} 
Ihes o significado." ${ }^{10}$ (HARDT \& NEGRI, 2018, p. 16). Lutar com palavras é coisa que, afinal, sabemos e podemos fazer! Então, por que não?

\subsection{Ampliar o engajamento numa efetiva reforma das licenciaturas}

Se a reforma das licenciaturas era, por um lado, necessária, tendo em vista a complexidade exigida para a formação de um professor, por outro, já explicitava como um de seus motores a lógica de mercado que se tornaria cada vez mais presente na Educação, conforme já se lê no Parecer CNE/CES 492/2001: “Concebe-se a Universidade não apenas como produtora e detentora do conhecimento e do saber, mas, também, como instância voltada para atender às necessidades educativas e tecnológicas da sociedade."

Hoje, após quatro anos de vigência da Resolução CNE/CP 02/2015, que serviu de bússola para as reformas universitárias em matéria de licenciatura, teriam os cursos de licenciatura realmente conseguido uma revisão em seus currículos de modo a privilegiar a formação de um professor da educação básica? O que se conseguiu rever acerca dos dispositivos de avaliação, conforme previa o Parecer CNE/CES 1.363/2001? Abriu-se efetivamente espaço para a pesquisa na formação desse profissional, conforme preconizava a Resolução CNE/CP 01/2002, em seu Artigo $3 \circ$, inciso III?

Penso que, de modo geral, a resposta a todas essas perguntas seja negativa. Agravando ainda mais as condições em que se realiza a Educação Básica, outras tantas negligências vão montando o quadro desolador do trabalho nas escolas com o qual hoje deparamos. Com efeito, a Resolução CNE/CP 02/2015 previa em seu artigo 18, parágrafo 3ำ, em capítulo referente à valorização do pessoal do magistério, determinadas cláusulas de qualidade que destinavam um terço da carga horária de trabalho do professor a outras atividades pedagógicas inerentes ao exercício do magistério, a exemplo da preparação de aulas, orientação, acompanhamento e avaliação de estudantes, reunião com pais, conselhos ou colegiados escolares, reuniões e grupos de estudos e/ou de trabalho, de coordenação pedagógica e gestão da escola, além das atividades de desenvolvimento profissional. Diante do grande número de atividades listadas a serem incluídas nessa terça parte, e cientes da pesada carga de atividades que, na escola, caracteriza o

\footnotetext{
10 Infatti uno dei compiti crucialidel pensiero politico è di dare battaglia sui concetti, chiarificandone o trasformandone il significato.
} 
trabalho do professor para além da sala de aula, sabemos que tal dispositivo legal está longe de se tornar realidade no cotidiano dos professores. E isso tanto na rede privada quanto na rede pública de ensino. Ou seja, o Estado que legisla acerca da formação e do trabalho de professores é o mesmo Estado que descumpre o instituído.

Penso que uma reação devesse ser assumida minimamente por aqueles a quem tal legislação interessa. Se é mais difícil uma reação por parte do próprio professor que, diante de uma maior fragilização dos sindicatos na atualidade, se sente desamparado e mesmo ameaçado de perder seu lugar de trabalho - penso aqui no âmbito do privado -, talvez coubesse uma ação mais incisiva por parte das unidades universitárias responsáveis pela formação desses professores. Afinal, é o destino dos profissionais que são formados pela universidade que está em jogo, o que coloca em risco a própria seriedade do trabalho que ali se realiza.

O que vimos assistindo, parece, é o oposto. Não creio que os formadores de professores que atuarão na Educação Básica tenham um grande orgulho da função para a qual estariam preparando seus alunos na universidade. O próprio aluno muitas vezes manifesta um não desejo de fazer parte dos quadros da Educação Básica. Muitas vezes encontrei graduandos que, desejando se tornar professores, não se dispunham a entrar em uma escola; queriam, sim, permanecer na universidade, tornando-se professores no ensino superior. Talvez seja exatamente por considerar como menor o trabalho na Educação Básica que esse professor universitário ${ }^{11}$ não deseja - não sabe? - repensar a formação do licenciando, e isso só ajuda o descaso governamental, incentivando esse tipo de reformas que, depois, "incompreensivelmente" eu diria, com alguma ironia, acabam "caindo de paraquedas sobre nossas cabeças".

\subsection{Opor resistência ao Programa Future-se}

Se nossa ação tem sido insuficiente em muitas situações, ainda é tempo de uma resposta mais efetiva no caso do programa Future-se. Iniciemos definindo nosso alvo - o programa Futurese -, descartando os homônimos indesejáveis. Numa rápida busca no Google, Future-se é

\footnotetext{
${ }^{11}$ Há, com efeito, muitos docentes atuando na educação superior que nunca passaram pela experiência da educação básica, ou então dela já se afastaram há muito tempo. Há, inclusive, aqueles que, tendo certa vez tido tal experiência, já a apagaram de seus currículos Lattes.
} 
também uma espécie de slogan da Faculdade de Informática e Administração Paulista (FIAP), que oferece cursos de graduação e MBA (online e presenciais). E mais: é o nome de um blog no qual se oferecem serviços de coaching profissional e pessoal. Mas aqui, não falo nem de um caso, nem de outro. Falo do programa destinado a universidades e institutos federais, lançado pela Secretaria de Educação Superior (SESu) do MEC em reunião com reitores em 17 de julho de 2019, o qual, alterando a LDB e outras dezesseis leis, assim se define em seu sítio: “(...) programa para fortalecer a autonomia financeira das universidades e dos institutos federais, por meio de ações de governança, gestão, empreendedorismo, pesquisa, inovação e internacionalização do ensino superior." (BRASIL, 2019).

A proposta do MEC considera que hoje a universidade vive problemas não de recursos, mas de gestão desses recursos, posição que está longe de ser consensual, principalmente depois do recente contingenciamento praticado pelo governo federal no 1o semestre de 2019. Trata-se de proposta que pode ser lida na íntegra em página de consulta pública que esteve inicialmente aberta até 07 de agosto de 2019 e que, posteriormente, foi prorrogada até o dia 29 do mesmo mês. Após preenchimento de cadastro, o interessado poderá acessar os nove trechos do texto, fazendo seus comentários ${ }^{12}$. Diga-se de passagem que, no último dia 26 de julho, as universidades e institutos federais do estado do Rio de Janeiro divulgaram nota conjunta acerca do Future-se, na qual explicitam que a insuficiência de detalhamento do programa impede sua análise mais aprofundada ${ }^{13}$. Já o Conselho Universitário da Universidade Federal do Amazonas tirou moção de repúdio ao Programa em 01 de agosto. O sítio do governo prevê uma nova redação da proposta na qual serão incorporadas as contribuições recebidas e promete seu posterior envio ao Congresso Nacional, sob a forma de projeto de lei. Uma promessa que, na realidade, se revela uma ameaça.

\footnotetext{
${ }^{12}$ Diga-se de passagem que, em 26 de julho de 2019, as universidades e institutos federais do estado do Rio de Janeiro, entre os quais o Colégio Pedro II, divulgaram nota conjunta na qual fazem uma análise do Future-se, explicitando que a insuficiência de detalhamento do programa impede outras considerações. Colocam-se à disposição de novos debates, sempre assentados nos princípios constitucionais e republicanos.

${ }^{13}$ Assinam a referida nota a Universidade Federal do Rio de Janeiro (UFRJ), a Universidade Federal Fluminense (UFF), Universidade Federal Rural do Rio de Janeiro (UFRRJ), Universidade Federal do Estado do Rio de Janeiro (Unirio), do Instituto Federal de Educação, Ciência e Tecnologia Fluminense (IFF), Instituto Federal de Educação, Ciência e Tecnologia do Rio de Janeiro (IFRJ), do Colégio Pedro Il e o diretor-geral do Centro Federal de Educação Tecnológica Celso Suckow da Fonseca (Cefet/RJ).
} 
Nesse mesmo sítio, diz-se que, ao longo da gestação do projeto, "inúmeros especialistas foram consultados e puderam contribuir para o aperfeiçoamento do programa" (Brasil, 2019). Em entrevista realizada com profissionais da educação, porém, critica-se que, além da falta de informações mais detalhadas sobre o programa, nem a Associação Nacional dos Dirigentes das Instituições Federais de Ensino Superior (ANDIFES), associação que reúne os reitores das instituições federais de ensino superior, nem as Associações de professores ou as associações científicas tenham sido consultadas para a elaboração do programa. Também não se ouviu o CONFIES, Conselho Nacional das Fundações de Apoio às Instituições de Ensino Superior e de Pesquisa Científica e Tecnológica, organismo que atualmente reúne as fundações de apoio que gerem os convênios já existentes entre a iniciativa privada e as universidades públicas.

Se convênios com a iniciativa privada já existem, parece não haver motivo para uma nova proposta que, segundo Baggio (2019), professora de História da UFMG, compromete a "liberdade de expressão" e submete a universidade às "amarras dos interesses empresariais e privados" e ao imperativo dos lucros, como é regular em um modelo privado de gestão. Ciente de que a única resposta possível à pergunta que coloca é negativa, Baggio questiona se a iniciativa privada estará interessada em financiar pesquisas críticas, voltadas, por exemplo, para questões como as que se seguem:

“(...) escravidão e a condição dos negros no pós-abolição, a concentração fundiária no Brasil, o domínio da mídia por oligopólios familiares, medicina preventiva e financiamento da saúde pública, as brutais desigualdades sociais e regionais do país, a desestabilização da democracia brasileira nos últimos anos, só para citar alguns temas relevantes? (BAGGIO, 2019)

Esse é certamente o risco que correm a pesquisa básica e as pesquisas não voltadas para os interesses do mercado. Esse também é o entendimento da professora de Letras e ex-reitora da UFJF, Margarida Salomão, ao declarar, em entrevista sobre o programa Future-se, que os recursos próprios gerados pela universidade, no Brasil e no resto do mundo, são de ordem complementar, cabendo ao poder público sustentar as atividades de formação, de pesquisa e de desenvolvimento. Acrescente-se o fato de a desresponsabilização do governo produzir forte impacto negativo nas políticas de redução das desigualdades educacionais. Segundo Salomão (2019), "confunde-se, malignamente, autonomia universitária com desresponsabilização do 
estado frente à educação superior". Ainda segundo a entrevistada, aquilo que no contexto empresarial se chama "empreendedorismo" manifesta-se, na universidade, como "autonomia intelectual e inteligência crítica".

"Darwinismo acadêmico em que cabe ao mercado decidir quais são os mais aptos" é a definição que Miguel (2019) faz do programa. Na opinião do professor de ciência política da UNB, é preciso oferecer uma resposta incisiva a tal armadilha. O que não lhe parece certo no momento. O professor justifica sua opinião:

Eu me pergunto se seremos capazes de dar esta resposta. Até agora, nossas organizações reagiram mal ao golpe e ao bolsonarismo. Resistem a admitir que o governo é formado por nossos inimigos e continuam fazendo o teatrinho do diálogo republicano - por exemplo, quando Bolsonaro declarou que as universidades não produzem conhecimento ou quando Weintraub disse que as ciências humanas não servem para nada, saíram educadas notas dizendo que eles estavam "mal informados", em vez da denúncia forte de que era o obscurantismo falando. (MIGUEL, 2019)

O dia 13 de agosto de 2019 foi escolhido como o Dia Nacional de Mobilizações, Assembleias, Paralisações e Greves, tendo em vista, além dos ataques à educação superior representados pelo programa Future-se, a ameaça da reforma da previdência que avança, em detrimento de muitos direitos dos trabalhadores.

\section{Por que as humanidades incomodam?}

A ênfase deste texto acaba sendo o conjunto de medidas que têm por objetivo desconstruir a educação pública, gratuita, de qualidade socialmente referenciada. Um mesmo texto reunindo fatos voltados para a saúde, por exemplo, mereceriaa ser construído, mas, aqui, interessa-me diretamente pensar o sentido de todos os ataques que temos mencionado ao mundo das humanidades. $E$, a esse respeito, uma primeira tarefa que se impõe é saber o que se entenderá por tal expressão, uma vez que não se trata de termo monossêmico.

Segundo Denizot (2015), humanidades é um termo empregado no contexto francês desde o advento da modernidade para se referir ao que se ensinava na escola com base no estudo da língua latina e dos autores latinos, o grego aparecendo com menor ênfase. O objetivo a ser alcançado era o trabalho sobre a dimensão retórica da linguagem. Em tal contexto, veio se 
articular a leitura de autores franceses, vistos principalmente como tradutores, e mesmo imitadores, dos autores clássicos. Já a partir do século XVIII, com a importância crescente da língua e da literatura francesas, contestou-se tal modelo de ensino, para se chegar, finalmente, à reforma do ensino de 1902, que marcou o final dessas humanidades ditas "clássicas", dando lugar a uma nova compreensão de humanidades, adjetivadas como "científicas" ou "modernas"14. Um novo modelo de educação inaugurou, então, a autonomização de disciplinas como a história e a literatura, e às línguas clássicas se substituíram as línguas modernas. O termo "humanidades" ganhou novos empregos diversificados no ensino superior francês no século XX, chegando em alguns casos a incluir estudos de Letras, filosofia, história, e ainda arqueologia, ciências da educação, ciências da comunicação, dentre outros.

Paralelamente ao emprego do termo humanidades, que aparece mais frequentemente no âmbito do ensino superior, assiste-se no contexto francês à introdução do termo "cultura humanista", mais usual nos ensinos primário e secundário. Aliás, a própria versão de 2006 da base comum de conhecimentos e de competências ${ }^{15}$ do Ministério da Educação Nacional na França reconhece, dentre suas sete competências, uma que se define como "cultura humanista". Se a expressão se referia no século XIX ao que anteriormente se chamou de "humanidades clássicas", como integrante da base comum ela diz respeito a estudos de literatura, artes, história, geografia, dentre outros (DENIZOT, 2015, p. 5).

Esse breve resumo do que vem sendo compreendido por "humanidades" tem por objetivo facilitar nossa reflexão a respeito do que estaria motivando os reiterados ataques sofridos, a exemplo da recente notícia do governo federal de não incentivo às áreas de sociologia e filosofia. Uma razão sempre apontada para o referido descaso de áreas como essas é a qualidade do retorno financeiro, sempre insuficiente, dos investimentos que nelas se fazem. Não foi outra, aliás, a argumentação do ministro Weintraub, apoiada pelo presidente da república,

\footnotetext{
${ }^{14}$ Sem contar que, no decorrer do século XX, ainda se introduzem as humanidades ditas técnicas ou profissionais, e também as humanidades digitais (DENIZOT, 2015, p. 3)

${ }^{15} \mathrm{~A}$ base comum de conhecimentos, de competências (socle commun de connaissances et de compétences), instituída pelo decreto 2006-830, de 11 de julho de 2006, apresenta o que o aluno deve dominar ao final do período de escolaridade obrigatório. Em sua versão reformulada pelo decreto 2015-372, de 31/03/2015, passa a se denominar "base comum de conhecimentos, de competências e de cultura" e, ao invés de sete competências, elenca cinco domínios de formação, dentre os quais não mais se fala de "cultura humanista", figurando, contudo, um quinto domínio intitulado "representações de mundo e atividade humana". Sobre o tema, ver também Mokadden (2015).
} 
quando indicou ser preciso "focar em áreas que gerem retorno imediato ao contribuinte, como veterinária, engenharia e medicina" (O GLOBO, 2019). Acredito, contudo, que a questão do retorno financeiro seja uma razão menor. Ou, antes, mero pretexto para se consolidar um projeto muito mais significativo, como o que embala os sonhos do regime de acumulação do atual capitalismo financeiro. Explico-me, valendo-me, para pensar a situação de vulnerabilidade das humanidades, da reflexão feita por Tatián (2017) a respeito daquilo que, na função docente - e, em especial, na função docente que se exerce no contexto da educação pública - se revela incompatível com uma perspectiva neoliberal: no exercício público de ensino e produção de conhecimento, há algo que não pode ser reduzido à lógica do capital, pelo simples fato de ser algo que é da ordem da gratuidade, e o gratuito é absolutamente desestabilizador para a lógica capitalista (TATIÁN, 2017): promessa de um conjunto de relações sociais reticentes à exploração, à apropriação do trabalho e do produto do trabalho de outros, ao reino da mercadoria e à dominação ideológica". ${ }^{16}$.

Assim, pelas mesmas razões que assistimos a tentativas de degradação crescente do trabalho docente ${ }^{17}$, a reiteradas investidas contra a educação pública, presenciamos na atualidade, em âmbito mais abrangente, os mesmos ataques contra tudo o que possa lembrar uma ação de caráter humanista, compreendida nos mesmos moldes utilizados para caracterizar a educação pública: uma ação que, irredutível à lógica do capital, "encerra a promessa de uma comunidade de iguais" (Tatián, 2017). É nesse sentido que as humanidades me parecem obstruir a dinâmica do capitalismo. Por isso as humanidades têm sido atacadas, e por isso é preciso cada vez mais investir em atos de resistência e invenção. E dizer que são as humanidades que estão correndo risco já será um eufemismo na atual conjuntura. Na verdade, tudo estará correndo risco, quando se declara que "nós queremos uma garotada que comece a não se interessar por política, como é atualmente dentro das escolas (...)" (LINDNER, 2019), declaração cujo absurdo se mostra por inteiro quando entendemos que interessar-se por política significa manter-se

\footnotetext{
${ }^{16}$ No original, "promesa de un conjunto de relaciones sociales reticentes a la explotación, a la apropiación del trabajo y del producto del trabajo de otros, al reino de la mercancía y a la dominación ideológica".

${ }^{17}$ Conforme se verifica no dispositivo da lei da Reforma do Ensino Médio (Lei 13.415/2017), que autoriza profissionais com notório saber a exercer na educação básica a função e professores.
} 
presente e atento às forças em luta aqui e agora, experimentando sintonia com o tempo que vivemos e corresponsabilização pelo espaço que compartilhamos.

Penso que, se, no momento, vivemos todos esses ataques a tudo aquilo que convencionamos chamar de humanidades, isso se explica, pelo menos parcialmente, pelo deslocamento sofrido pelo conceito desde sua acepção clássica até sua versão repensada na atualidade: as humanidades não mais entendidas em sua acepção clássica, como recuperação de um modelo universal de homem. Talvez mesmo nesse antigo sentido as humanidades ameaçassem menos. O fato, porém, é que a ênfase agora se coloca no relativismo que caracteriza o conceito, responsável por mostrar que, a cada época, valores e formas de pensar e de sentir o mundo vão conviver e vão se alterar. Uma nova concepção que expõe à crítica certas conformações de vida em sociedade que hoje privilegiam a mera reprodução de hábitos de um tempo passado. E isso é tudo o que as formações hegemônicas estabilizadas não querem ouvir.

\section{Macropolítica e micropolítica}

No início deste texto, fiz menção à necessidade de uma autocrítica, e isso porque, com Rolnik (2018), considero que as dificuldades que atravessamos neste ano de 2019 não podem ser explicadas unicamente pela ação das forças adversas. Há algo na própria configuração de nossas lutas que produz um sentimento de impotência de que muitos se queixam na atualidade.

O que temos feito diante de todas as graves ameaças que vimos sofrendo? Ou o que será que ainda não fizemos e que é preciso fazer diante de tal situação? Temos, com certeza, manifestado nossa opinião acerca das situações inusitadas a que assistimos, temos participado das manifestações de rua, temos reafirmado os princípios de educação que desejamos, temos, enfim, dito que tipo de sociedade pretendemos construir. Mas parece que isso não tem sido o bastante.

Reconhecemos com Guattari (1986) a importância das lutas pela democracia que ganham corpo nas grandes organizações políticas e sociais. Lutas que se dão num plano dito macropolítico. Na realidade, participamos de grandes movimentos que dão visibilidade a um dado acordo estabelecido entre sujeitos que racionalmente decidem agir, em atitude de afrontamento, para a defesa de um dado modo de existência que se deseja preservar (ou recuperar), repensando as relações de poder instituídas entre os agentes identitários em cena. 
É o que ocorre na disputa entre uma medida governamental que desagrada (por exemplo, o recente programa Future-se) e a reação desencadeada a partir de então (depoimentos contrários e chamada para uma manifestação nas ruas no dia 13 de agosto de 2019). Estes são movimentos que Rolnik situa no plano do "empoderamento do sujeito", movimentos situados em um plano de insurgência macropolítica. Um modo de ação necessário, mas, como já dissemos, insuficiente.

E por que falamos de insuficiência? Ora, porque, como lembra Guattari, essas lutas só se consolidam, só ganham consistência, se puderem tocar um além do sujeito da razão, isto é, se puderem afetar a subjetividade dos indivíduos e dos grupos em níveis moleculares, lá onde conseguirão gerar novas atitudes, novas sensibilidades, novas conexões, que impedirão a volta de velhas estruturas (GUATTARI, 1986, p. 134). Afetar um plano micropolítico, esse é o desafio. Reencontramos aqui o mesmo tipo de preocupação reiterado por Hardt e Negri (2018, p. 9), quando falam dos efeitos pouco duradouros dos movimentos sociais que lutam pela democracia. Nossas conquistas não têm tido longo fôlego. As conquistas das esquerdas não têm tido longo fôlego. Parece que algo está faltando! E esse algo que é preciso recuperar é a dimensão micropolítica, tarefa que Rolnik (2018, p. 117-118) nos ajuda a concretizar: "como é apenas na esfera macropolítica que elas [as esquerdas tradicionais] atuam, o resultado de suas ações permanece confinado na própria forma de mundo que sua (nossa) luta tem como alvo." A autora reconhece a importância das ações no plano macropolítico, mas não deixa esquecer o plano micropolítico, pensado como "esfera das formações do inconsciente no campo social que definem os modos - direi, descolonizados - de existência" (ROLNIK, 2018, p. 118).

Nossos opositores parecem saber aproveitar os efeitos desse plano micro em situações variadas. Lembremos, por exemplo, algumas das iniciativas de ordem macropolítica assumidas recentemente num suposto combate à corrupção. Cito muito brevemente três exemplos que ainda devem estar na memória de todos os brasileiros: a prisão do reitor da Universidade Federal de Santa Catarina, professor Luiz Carlos Cancellier, em outubro de 2017, por denúncia de desvio de verbas de programas de ensino a distância; a detenção do reitor e da vice-reitora da Universidade Federal de Minas Gerais em dezembro de 2017, também acusados de desvio de recursos públicos; em setembro de 2018, a difamação do então reitor da Universidade Federal do Rio de Janeiro, professor Roberto Leher, por ocasião do incêndio do bissecular Museu 
Nacional do Rio de Janeiro ${ }^{18}$. É certo que, em todos esses casos, pudemos assistir a ações dos reformadores empresariais da educação ${ }^{19}$ no plano macropolítico, mas o que desejo no momento enfatizar são os efeitos micropolíticos que então se produziram: efeitos de (des)vitalização, em função dos afetos então mobilizados; de paralisação ou de aceleração de forças contrárias aos efeitos de desmoralização pessoal e do serviço público; enfim, efeitos ativos, que possibilitam a germinação de novos mndos, ou meramente reativos, que não fazem senão reafirmar um mesmo mundo como única possibilidade de composição de forças que se revelam corrosivas para as subjetividades, como ocorreu no episódio do suicídio do reitor em Santa Catarina.

São esses efeitos do plano micropolítico que ora desejo enfatizar - efeitos que não se deixam guiar por critérios racionais, mas pulsionais, nos quais se dá a germinação de novos embriões de mundos que poderão ou não se atualizar; um plano desestabilizador das certezas construídas na dimensão macropolítica, e que se movimenta não pela moral, mas pela ética, com base nos afetos que mobilizam cada um de nós. Plano gerador de tensão, de estranhamentos, como diz Rolnik (2018). Em resposta ao chamado desse plano, duas ordens de resposta são possíveis: uma resposta reativa, que busca de diversas maneiras evitar a desestabilização provocada pelas forças em jogo; uma resposta ativa, quando a subjetividade se permite tocar pelas ressonâncias desse plano, abrindo espaço para a potencialização da vida (Rolnik, 2018, p. 131-133). Forças em embate para alterar formas mais ou menos cristalizadas; formas buscando resistir ao máximo para não ceder às forças que oportunizam novos mundos.

Diante da questão que ora nos mobiliza (o ataque às humanidades), como temos procedido? Ativamente ou reativamente? Considerando que "as lutas sociais são, ao mesmo tempo, molares e moleculares ..." (GUATTARI, 1986, p. 127), a questão micropolítica que se coloca é a de "como reproduzimos (ou não) os modos de subjetividade dominantes" (GUATTARI, 1986, p. 133).

\footnotetext{
${ }^{18}$ Os ataques pessoais ao prof. Roberto Leher não deixaram de mencionar que se tratava de alguém filiado ao Partido Socialismo e Liberdade (PSOL), partido político brasileiro de esquerda fundado em 2004, conforme se verifica na notícia veiculada no sítio oantagonista.com/brasil/responsabilidade-psol-no-incendio-museu-nacional/. O Antagonista é um sítio web jornalístico que se apresenta como de direita, tendo sido criado pelos jornalistas Diogo Mainardi e Mário Sabino em 1o de janeiro de 2015.
}

${ }^{19}$ Ver Acselrad, 2018. 
O que seria então investir ativamente em um plano micropolítico, que é o que é necessário para dar passagem à produção de novos mundos, garantindo, assim, consistência a eventuais conquistas no plano macro? De que modo ir além do chamado "protesto programático das consciências" (Rolnik, 2018, p. 122)? Como ultrapassar o plano das ações macropolíticas uma macropolítica que, é claro, precisa existir - para se chegar a provocar no plano micropolítico uma "ação" - e não mera "reação" - de efeitos mais duradouros? Este é um desafio que só pode ser disputado coletivamente, penso. Ensaio aqui uma primeira versão de como vimos habitando o território da Educação, colocando o foco em iniciativas e atitudes que de alguma forma façam contato com uma micropolítica ativa. Com base na paisagem desenhada, essa micropolítica talvez tenha alguma chance de ir ganhando consistência. Como é que se pode pensar essa micropolítica, no nosso caso? Os seis tópicos que se seguem procuram sintetizar meu posicionamento a respeito.

Oportunizar encontros é o primeiro desses tópicos. Oportunizar encontros é investir no plano micropolítico ${ }^{20}$, pois ajuda a alterar sensibilidades, promovendo novas conexões, novas alianças. Quebrar o isolamento de uma lógica de categorias que separa universidade e educação básica, que afasta as diferentes disciplinas (línguas, de um lado, história, geografia, filosofia, etc., de outro). Em nosso cotidiano, também aprendemos a não nos reunir com pares, ou talvez nem saibamos exatamente com quem seria desejável formar pares; acho que, no máximo, o que fazemos é nos amontoar. Retomo Donizetti (2018), que nos alerta: “Não esqueça que é preciso mais do que nunca estar com as pessoas. Não é sem motivos que ditaduras em algum momento proíbam reuniões."

A segunda iniciativa é abrir espaço para os afetos no trabalho. Afetar e se deixar afetar nesse espaço. Acostumamo-nos a espaços não adequados de trabalho, tanto no que diz respeito ao espaço exíguo das salas de aula, quanto à precariedade de nossas salas de trabalho em equipe ou de repouso; tudo contribui para a nossa não permanência na escola/universidade. Diferentemente, os burocratas via de regra dispõem de salas espaçosas e muito mais bem equipadas. Dispor de espaço na lógica dos burocratas é exercer poder. Nas diferentes instituições de educação (escola, universidade), basta que avaliemos o metro quadrado destinado às

\footnotetext{
${ }^{20}$ Encontros exatamente como o que se realizou naquele dia 22 de agosto 2019 no Colégio Pedro II - campus Centro.
} 
burocracias e o que cabe a cada professor e alunos. Temos uma profissão que se exerce "no aperto". Diante das precárias condições de nossos espaços de trabalho, aprendemos a investir nossos afetos em outros espaços e em outros objetos situados fora do trabalho. A penúria de recursos que se disponibilizam para a Educação cumpre uma função, com certeza: tornar a escola / a universidade um lugar não desejado, um lugar em que não posso investir meus afetos; portanto, um espaço por mim não reivindicado.

Como terceira iniciativa, penso na ampliação de nossos espaços de fala. Aprendemos a não decidir coisas, ou a decidir apenas o supérfluo. Nossos espaços de fala são cada vez mais rarefeitos. Afinal, quando foi que nos manifestamos em relação à reforma do ensino médio, por exemplo? Os dispositivos de controle de nossos representantes são frágeis e morosos, e o tempo do funcionamento da burocracia atropela qualquer iniciativa de uma mais ampla participação na tomada de decisões. Na escola / universidade, também aprendemos a silenciar. Nada disso, certamente, é sem consequências.

Promover a autoestima é a quarta iniciativa para nos sincronizarmos com uma micropolítica ativa. Como profissionais que não falam, que ocupam espaços inapropriados e circunscritos ao mínimo, somos também profissionais que custam muito pouco. Nossa hora de trabalho é barata. Um panfleto relativo à campanha salarial de 2019 distribuído pelo Sinpro mencionava um piso salarial na rede privada de $\mathrm{R} \$ 13,63$ para Educação Infantil e Fundamental I e, para Fundamental II e Ensino Médio, $\mathrm{R} \$ 19,44$. Muitas lutas no plano macro ainda serão necessárias para combater tal situação, mas essas lutas não podem estar dissociadas de ações no plano micro como, por exemplo, a conquista da satisfação consigo mesmo, afeto tratado por Spinoza e que se aproxima da ideia de autoestima. Com efeito, ocorrendo sempre que alguém faz algo que "imagina afetar os demais de alegria"21, a satisfação consigo mesmo revela-se um afeto potencializador, uma vez que promove naquele que o experimenta a alegria de saber-se causa interior da afecção produzida. Caracterizando-se como oposta ao afeto que Spinoza denomina arrependimento, a satisfação consigo mesmo ocupará um lugar central no resgate de uma micropolítica ativa do trabalho do professor.

\footnotetext{
${ }^{21}$ Reflexão presente na proposição 30 da Terceira parte da Ética, de Spinoza.
} 
Quinta iniciativa: promover apreço pelo trabalho que fazemos. Em condições tão adversas, muitos pensam encontrar uma saída para o barateamento dos salários na desvalorização e no barateamento do próprio trabalho e, então, trabalha-se por baixo, trabalhase pelo mínimo, trabalha-se sem um investimento maior do desejo. Trabalha-se até certo ponto de forma anestesiada para não se viver mais agudamente o ressentimento que nos distancia do outro, incluindo-se nessa categoria de outridade em especial a profissão que se escolheu e que se exerce sem qualquer paixão, quando então os desejos e os desafios de um tempo passado vão aos poucos se adormecendo.

Finalmente, um sexto tópico importante como fundamentação para nossas lutas: reconhecer e estar atentos à dimensão micropolítica do trabalho em sala de aula. No caso particular dos profissionais que ensinam língua estrangeira - e eu me coloco como alguém que durante 38 anos trabalhou nesse recorte do vasto território das humanidades que é o do ensino de línguas -, vamos nos acostumando a que vejam nossa disciplina como uma concessão que se faz a um saber quase dispensável. Na escola, acostumamo-nos ao título de profissionais daquelas disciplinas que não reprovam - e ainda temos de suportar um diálogo com valores de sabor meritocrático, segundo os quais as disciplinas de peso são aquelas que reprovam. Não que haja algo de bom em reprovar, mas esse perfil de "disciplina supérflua" não nos convém como marca distintiva. Supérfluos é o que todos nós, professores de todas as disciplinas, estamos nos tornando quando, por exemplo, ministramos nossos cursos com uma quantidade de alunos incompatível com toda e qualquer forma de trabalho digno; e quando esperam que possamos digerir uma simplória massa de textos legais como a recente reforma do ensino médio. Dito de forma bem resumida, este é um quadro que muitas vezes leva o professor, seja de que disciplina for, a encontrar saídas meramente reativas, quando introjeta uma culpa dizendo, por exemplo, "sou um fracasso como professor, não dou pra isso"; ou então quando atribui culpa a um terceiro, e reclama dos alunos de hoje que "não querem nada", ou quando diz que "trabalhar em educação básica como professor é coisa menor". Uma longa sequência de paixões tristes orquestrada por uma micropolítica de culpabilização e de estagnação.

Procurei não falar sozinho nesse texto. Talvez devesse dizer "nesse nosso texto", uma vez que tive o cuidado de ler e reler jornais, reunir autores da academia e de fora dela. Se digo "nosso", é porque reconhecemos um campo que desejamos habitar e um outro que não seria 
nosso, mas "deles", um campo que não podemos compartilhar, já que construído segundo uma lógica da exclusão, da hierarquização, da submissão a valores transcendentes segundo os quais a vida ainda está por acontecer. Esse texto pretende ser uma fala coletiva. É por compartilhar um mesmo espaço de indignação que tenho algo a dizer, e dizer algo é condição para nos mantermos minimamente sadios. Ainda ter interlocutores, isso é bom!

\section{Referências}

ACSELRAD, H. Espectros do anti-intelectualismo tropical. Le Monde Diplomatique, Brasil, 21 set. 2018. Disponível em: https://diplomatique.org.br/espectros-do-anti-intelectualismo-tropical/. Acesso em: 12 jul. 2019.

BAGGIO, K. G. (2019). FUTURE-SE: o que dizer sobre o projeto do MEC para as universidades e institutos federais? Disponível em: https://www.viomundo.com.br/voce-escreve/katiagerab-baggio-o-que-dizer-do-future-se-projeto-do-mec-para-as-universidades-publicas.html. Acesso em: 21 jul. 2019.

BRASIL. Programa Future-se. Brasília: MEC, 17 jul. 2019. Disponível em: https://isurvey.cgee.org.br/future-se/. Acesso em: 20 jul. 2019.

BRUM, E. Bolsonaro e a autoverdade. El País, 16 jul. 2018. Disponível em: https://brasil.elpais.com/brasil/2018/07/16/politica/1531751001_113905.html. Acesso em: 2 ago. 2019.

DENIZOT, N. Les humanités, la culture humaniste et la culture scolaire. Tréma, Montpellier, $\mathrm{n}$. 43, p. 42-51, 2015. Disponível em: https://journals.openedition.org/trema/3301. Acesso em: 20 jul. 2019. Doi: https://doi.org/10.4000/trema.3301.

DONIZETTI, M. Manual de conduta e resistência ao controle do discurso e da libido. Forum, 03 nov. 2018. Disponível em: revistaforum.com.br/manual-de-conduta-e-resistencia-ao-controledo-discurso-e-da-libido/. Acesso em: 23 jul. 2019.

GUATTARI, F. Entrevistas diversas. In: GUATTARI, Félix; ROLNIK, Suely. Micropolítica cartografias do desejo. Vozes: Petrópolis, 1986.

HARDT, M.; NEGRI, A. Assemblea. Tradução italiana de Tania Rispoli. Milão: Ponte Alle Grazie, 2018.

LADEIRA, F. F. A era do anti-intelectualismo. Observatório da Imprensa, ed. 1020, 15 jan. 2019. Disponível em: http://observatoriodaimprensa.com.br/dilemas-contemporaneos/a-era-doanti-intelectualismo/. Acesso em:13 jul. 2019.

LINDNER, J. Bolsonaro: 'Queremos uma garotada que comece a não se interessar por política'.
O Estado
de
S. Paulo,
09 abr.
2019.
Disponível
em: 
educacao.estadao.com.br/noticias/geral,bolsonaro-queremos-uma-garotada-que-comece-anao-se-interessar-por-politica,70002785320. Acesso em: 28 jul. 2019.

MAingueneAU, D. Posicionamento. In: CharaudeAu, P.; MAINGUENEAU, D. Dicionário de Análise do Discurso. Coord. de trad. Fabiana Komesu. São Paulo: Contexto, 2004.

MIGUEL, L. F. Universidade não precisa de "empreendedorismo", mas de pensamento crítico, 18 jul. 2019. Disponível em: https://jornalggn.com.br/artigos/universidade-nao-precisa-deempreendedorismo-mas-de-pensamento-critico-por-luis-felipe-miguel/. Acesso em: 21 jul. 2019.

MOKADDEM, S. La culture humaniste à l'École. Remarques sur la notion de «culture humaniste» et sur la formation au sein des ESPE dans le processus d'accompagnement des enseignant-e-s. Tréma - revue internationale en sciences de l'éducation et didactique, Montpellier, v. 43, p. 101-111, 2015. Disponível em: journals.openedition.org/trema/3339. Acesso em: 13 jul. 2019. https://doi.org/10.4000/trema.3339.

O GLOBO. 2019. Educação. Disponível em: g1.globo.com/educacao/noticia/2019/04/26/bolsonaro-diz-que-mec-estuda-descentralizarinvestimento-em-cursos-de-filosofia-e-sociologia.ghtml. Acesso em: 12 jul. 2019.

ROLNIK, S. Esferas da insurreição - notas para uma vida não cafetinada. São Paulo: n-1 edições, 2018.

SALOMÃO, M. Future-se: a não-solução para um falso problema. Diário do Centro do Mundo, 19 jul. 2019. Disponível em: https://www.diariodocentrodomundo.com.br/future-se-a-naosolucao-para-um-falso-problema-por-margarida-salomao/. Acesso em: 21 jul. 2019.

SANTOS, B. de S. A difícil democracia - reinventar as esquerdas. São Paulo: Boitempo, 2016.

SOLANO, E. Crise da democracia e extremismos de direita. Pesquisa financiada pela Fundação Friedrich Ebert - Friedrich-Ebert-Stiftung (FES). Maio 2018. Disponível em: http://library.fes.de/pdf-files/bueros/brasilien/14508.pdf. Acesso em: 3 ago. 2019.

SPINOZA, B. de. Ética. Trad. de Tomaz Tadeu. Belo Horizonte: Autêntica, 2007.

TATIÁN, D. Un mundo sin docentes. El País, 25 abr. 2017. Disponível em: pagina12.com.ar/33858-un-mundo-sin-docentes. Acesso em: 18 jun. 2019.

TIBURI, M.; CASARA, R. Ódio à inteligência: sobre o anti-intelectualismo. Em Pauta, 13 out. 2016. Disponível em: https://www.geledes.org.br/odio-inteligencia-sobre-o-anti-intelectualismo/. Acesso em: 12 jul. 2019. 